\title{
Correlação entre a contagem automática de células somáticas e a porcentagem de neutrófilos pela citometria de fluxo e pela técnica de citocentrifugação
}

\author{
[Correlation between automatic somatic cell count and the percentage of neutrophils through flow \\ cytometry and cytocentrifugation technique] \\ C.S. Mira ${ }^{1}$, A.M.M.P. Della Libera ${ }^{2}$, F.N. Souza ${ }^{3}$, M.G. Blagitz ${ }^{1 *}$ \\ ${ }^{1}$ Escola de Veterinária - Universidade Federal do Paraná - Palotina, PR \\ ${ }^{2}$ Faculdade de Medicina Veterinária e Zootecnia - Universidade de São Paulo - São Paulo, SP \\ ${ }^{3}$ Escola de Veterinária - Universidade Federal de Minas Gerais - Belo Horizonte, MG
}

\begin{abstract}
RESUMO
O objetivo do presente estudo foi avaliar a correlação entre a contagem automática de células somáticas (CCS) com a porcentagem de neutrófilos pela técnica de citocentrifugação e pela citometria de fluxo. Para tal, 102 amostras de leite proveniente de 28 vacas da raça Holandesa foram coletadas e submetidas ao isolamento de células do leite e posterior identificação da população de neutrófilos. Após citocentrifugação, os neutrófilos foram identificados por microscopia óptica utilizando-se o corante de Rosenfeld. Os neutrófilos lácteos foram identificados por citometria de fluxo utilizando anticorpo monoclonal específico (CH138A) e anticorpo monoclonal secundário conjugado à ficoeritrina. O presente estudo demonstrou correlação positiva entre a CCS e a porcentagem de neutrófilos por citometria de fluxo $(r=0,625)$ e pela técnica de citocentrifugação $(r=0,267)$. Observou-se também correlação positiva entre a porcentagem de neutrófilos pela citometria de fluxo e pela técnica de citocentrifugação $(r=$ 0,496), embora a porcentagem de neutrófilos no leite tenha sido maior pela técnica de citocentrifugação quando comparada com a citometria de fluxo. Deste modo, o presente estudo indica que a citometria de fluxo pode ser uma ferramenta útil no diagnóstico e controle da mastite bovina.
\end{abstract}

Palavras-chave: bovinos leiteiros, contagem celular diferencial, glândula mamária, leucócitos polimorfonucleares, mastite

\begin{abstract}
The purpose of the present study was to assess the correlation between the automatic somatic cell count (SCC) and the percentage of neutrophils through cytocentrifugation technique and flow cytometry. Thus, 102 milk samples from 28 Holstein dairy cows were collected and submitted to milk cell isolation procedures, and afterwards, the neutrophils were identified. After cytocentrigugation, the neutrophils were microscopically identified using the rosenfeld dye. The milk neutrophils were recognized by flow cytometry using primary mouse IgM monoclonal antibody (CH138A) and phycoerytrin (PE) goat antimouse IgM antibody. This study found a positive correlation between SCC and the percentage of neutrophils through cytocentrifugation $(r=0.267)$ and flow cytometry $(r=0.625)$. A positive correlation was also encountered between the percentage of neutrophils through cytocentrifugation and flow cytometry $(r=0.496)$, although the percentage of neutrophils was higher in samples submitted to cytocentrifugation. In conclusion, flow cytometry can be a useful tool in the diagnosis and control of mastitis.
\end{abstract}

Keywords: dairy cows, differential cell count, mammary gland, mastitis, polymorphonuclear leukocytes

Recebido em 31 de outubro de 2012

Aceito em 4 de fevereiro de 2013

*Autor para correspondência (corresponding author)

E-mail: magblagitz@uol.com.br 


\section{INTRODUÇÃO}

A contagem de células somáticas (CCS) é um parâmetro amplamente utilizado para monitorar a saúde do úbere e a qualidade do leite. A celularidade do leite é influenciada por vários fatores, entre eles número de lactações, condições climáticas, raça e idade do animal, época do ano, manejo e nutrição, mas a infecção da glândula mamária é considerada o principal fator que leva ao aumento da celularidade do leite (Pyörälä, 2003; Cunha et al., 2008; Della Libera et al., 2011). A CCS determina todos os tipos celulares presentes no leite, não fazendo a diferenciação entre os distintos tipos celulares, que incluem as células epiteliais, os linfócitos, os macrófagos e osneutrófilos (Koess e Hamann, 2008).

O aumento da CCS no leite durante o processo infeccioso da mama ocorre principalmente devido ao rápido e massivo influxo de neutrófilos para a mama (Pyörölä, 2003; Della Libera et al., 2011). Embora a contagem microscópica de células somáticas seja um método comum para a determinação da contagem diferencial de células presentes no leite, ela consome bastante tempo e apresenta baixa repetibilidade, devido a sua subjetividade (Koess e Hamman, 2008). Em contraste, a citometria de fluxo é o método automático e rápido, que permite a contagem de expressivo número de células em curto espaço de tempo (Rivas et al., 2001; Dosogne et al., 2003; Koess e Hamman, 2008; Piepers et al., 2009). Isto acarreta em resultados mais precisos e menos trabalhosos do que a citologia convencional. Tal método tem a vantagem também de permitir a detecção do processo inflamatório logo no início, quando ainda a CCS está baixa (Redelman et al., 1988; Koess e Hamann, 2008), aumentando a confiabilidade dessa ferramenta no diagnóstico da mastite e favorecendo o sucesso do tratamento dessa enfermidade, que é maior logo no início da infecção (Koess e Hamann, 2008).

Diante do exposto, o objetivo deste estudo foi avaliar a correlação entre automática contagem de células somáticas (CCS) e porcentagem de neutrófilos $\left(\mathrm{CH} 138^{+}\right)$por citometria de fluxo e pela técnica de citocentrifugação.

\section{MATERIAL E MÉTODOS}

Foram utilizadas 28 vacas (109 quartos mamários) da raça Holandesa, mantidas em sistema de produção conforme as exigências para a produção de leite do tipo B (Brasil, 2002). Após a higienização dos tetos, a antissepsia com solução de álcool a 70\% o e descarte dos primeiros jatos de leite, coletaram-se as amostras de leite em três alíquotas. A primeira foi coletada para a contagem de células somáticas (SCC) automática. A segunda alíquota foi coletada para a quantificação de neutrófilos pela técnica de citocentrifugação. A terceira alíquota foi destinada à avaliação e à quantificação de neutrófilos $\mathrm{CH} 138^{+}$pela técnica de citometria de fluxo. Após a coleta das amostras de leite, as vacas foram ordenhadas conforme os padrões estabelecidos pela fazenda.

As amostras da primeira alíquota foram coletadas em frascos com o conservante bronopol e encaminhadas para a CCS automática. O material foi acondicionado em caixas isotérmicas e enviado para análise no laboratório da Escola Superior de Agricultura "Luiz de Queiroz" (Esalq-USP) credenciado ao Ministério da Agricultura Pecuária e Abastecimento.

Para a segunda alíquota, $25 \mathrm{~mL}$ de leite foram coletados em frascos com capacidade de $50 \mathrm{~mL}$ contendo $25 \mathrm{~mL}$ de solução salina tamponada (SST). No laboratório, essas amostras foram inicialmente centrifugadas a $250 \mathrm{~g}$ por oito minutos a $4^{\circ} \mathrm{C}$. Em seguida, o sobrenadante foi desprezado e o botão celular sedimentado foi ressuspendido com SST até o volume inicial da amostra. Após a segunda centrifugação, o botão celular foi ressuspendido com $1 \mathrm{~mL}$ de SST. Alíquotas de $200 \mathrm{uL}$ da suspensão celular foram submetidas à citocentrifugação (Cytospin, Incibras ${ }^{\circledR}$, Brasil) a $28 \mathrm{~g}$ durante seis minutos. A partir do sedimento, confeccionaram-se lâminas em duplicatas, que foram coradas pelo corante de Rosenfeld, para então serem contadas e diferenciadas 400 células em microscopia de campo claro $(1000 x)$ e determinada a porcentagem de neutrófilos.

As amostras da terceira alíquota foram coletadas em aproximadamente $200 \mathrm{~mL}$ de leite por amostra em frascos com capacidade para $500 \mathrm{~mL}$. Em cada frasco, foram colocados $100 \mathrm{~mL}$ de SST e $100 \mathrm{~mL}$ de leite. Estas foram mantidas e 
encaminhadas ao laboratório sob refrigeração. No laboratório, as amostras foram centrifugadas a $1.000 \mathrm{~g}$ por 15 minutos $\left(4^{\circ} \mathrm{C}\right)$, conforme as orientações de Koess e Hamann (2008). Após a centrifugação, o sobrenadante foi desprezado pela inversão única do frasco. O botão celular foi ressuspendido pela aspersão gentil de aproximadamente $30 \mathrm{~mL}$ de SST. Em seguida, as amostras foram centrifugadas a $400 \mathrm{~g}$ por 10 minutos $\left(4^{\circ} \mathrm{C}\right)$. Posteriormente, desprezou-se o sobrenadante, e o botão celular foi ressuspendido em aproximadamente $10 \mathrm{~mL}$ de SST. As amostras foram novamente centrifugadas a $400 \mathrm{~g}$ por 10 minutos a $4^{\circ} \mathrm{C}$. Finalmente, desprezou-se o sobrenadante, e as células foram ressuspendidas em $1 \mathrm{~mL}$ de meio de cultivo celular (RPMI-1640, Sigma Aldrich, $\mathrm{n}^{\circ}$ cat. R7638, EUA) enriquecido com soro fetal bovino (Cultilab, Brasil) a $10 \%$ (Koess e Hamann, 2008).

Após a formação do botão celular, a contagem celular foi realizada em câmara de Neubauer, e a viabilidade celular foi avaliada pela exclusão do azul de tripan (Merck, Alemanha). Em seguida, a suspensão celular foi ajustada em $2 \times 10^{6}$ células viáveis $/ \mathrm{mL}$ para a realização da imunofenotipagem por citometria de fluxo (FACSCalibur $^{\mathrm{TM}}$ - Becton Dickinson Immunocytometry System $^{\mathrm{TM}}$, BD Biosciences, EUA).

Posterior ao ajuste celular, foram adicionados $100 \mu \mathrm{L}$ da suspensão celular e $1 \mu \mathrm{L}$ do anticorpo

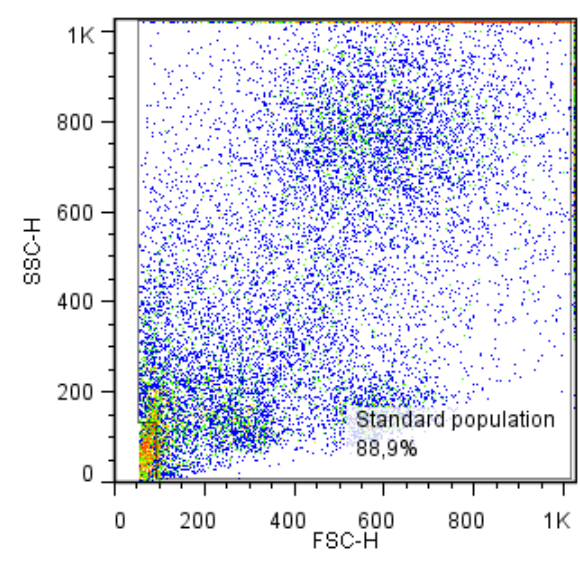

monoclonal primário mouse IgM anti-bovine CH138 (VMRD, Pullman, EUA, $\mathrm{n}^{\mathbf{0}}$ cat. CH138A) e incubaram-se as amostras por 30 minutos em temperatura ambiente. Após esse período, foram adicionados $1.000 \mu \mathrm{L}$ de SST e foi realizada a centrifugação a $250 \mathrm{~g}$ por oito minutos. Ressuspenderam-se as amostras em $100 \mu \mathrm{L}$ de SST com $1 \mu \mathrm{L}$ do respectivo anticorpo monoclonal secundário goat anti-mouse IgM conjugado ao fluorocromo ficoeritrina (PE) (Invitrogen, Carlsbad, EUA, no cat. M31504). As amostras foram incubadas por 30 minutos, à temperatura ambiente e sob ausência de luminosidade, para, então, adicionar $1.000 \mu \mathrm{L}$ de SST em cada tubo e submetê-los a nova centrifugação. Ao final, foram adicionados $300 \mu \mathrm{L}$ de SST suplementado com albumina sérica bovina a 0,1\% (Albumina Bovina Fração $\mathrm{V}$, cód. 1870. Inlab, Brasil). Foram adquiridos aproximadamente 20 mil eventos utilizando-se o programa CELLQUEST ${ }^{\circledR}$ (Becton Dickinson Immunocytometry Systems $^{\mathrm{TM}}$, EUA).

Os dados obtidos das leituras da citometria de fluxo foram analisados pelo software FlowJo (Treestar - versão 7.6.1 para Windows). Devido à presença de grande quantidade de debris celulares, os leucócitos foram localizados pelo tamanho e pela granulosidade (SSC x FSC). Em seguida, para a localização da população de leucócitos polimorfonucleares $\mathrm{CH} 138+$, a marcação com anticorpo monoclonal (CH138A) foi realizada. (Fig. 1).

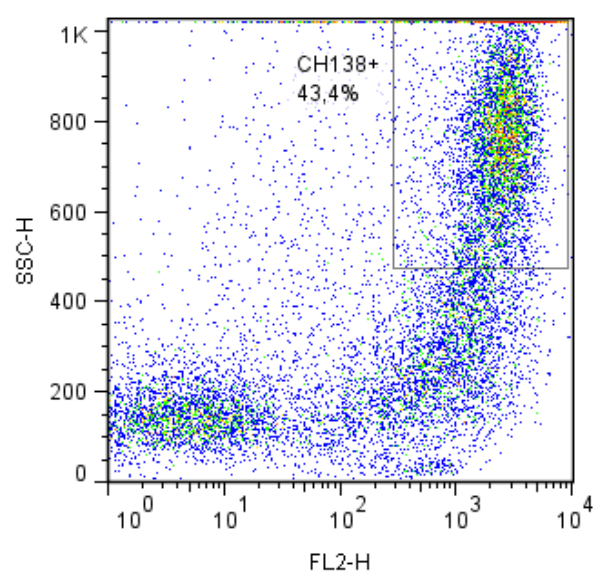

Figura 1. Identificação de neutrófilos isolados de amostra de leite. (A) Dot plot das propriedades de tamanho (forward scatter [FSC-H]) versus complexidade celular (side scatter [SSC-H]) realizada em 20 mil eventos delimitados pela população padrão, em que inicialmente se excluiu grande parte dos debris. (B) Dot plot demonstrando a complexidade celular versus CH138A-ficoeritrina (FL2-H) da população padrão, onde está delimitada a população de neutrófilos. 


\section{Mira et al.}

A correlação entre as variáveis foi realizada pela correlação de Spearman (dados não paramétricos). As comparações das porcentagens de neutrófilos pela citometria de fluxo e citocentrifugação foram analisadas pelo teste de Wilcoxon (Sampaio, 2010).

\section{RESULTADOS}

O presente estudo demonstrou correlação positiva entre a CCS automática e a porcentagem de neutrófilos por citometria de fluxo $(r=0,625$; $P<0,0001$ ) e pela técnica de citocentrifugação ( $\mathrm{r}=0,267 ; P=0,0068$ ). Observou-se também correlação positiva entre a porcentagem de neutrófilos pela citometria de fluxo e pela técnica de citocentrifugação $\quad(r=0,496$; $P<0,0001$ ) (Tab. 1), embora a porcentagem de neutrófilos no leite tenha sido maior pela técnica de citocentrifugação $(50,32 \pm 27,47)$ quando comparada com a citometria de fluxo $(25,71 \pm 21,24 ; P<0,0001)$ (Tab. 1).

Tabela 1. Porcentagem de neutrófilos no leite de vacas Holandesas em lactação pela técnica de citocentrifugação e pela citometria de fluxo, e sua correlação

\begin{tabular}{lcccc}
\hline & \multicolumn{4}{c}{ Porcentagem de neutrófilos } \\
\cline { 2 - 5 } Técnica & Até 200.00 & Entre 200.001 & Acima de & \\
& células/mL & células $/ \mathrm{mL}$ e & 400.000 & Total \\
& $(\mathrm{n}=64)$ & 400.000 & células $/ \mathrm{mL}$ & $(\mathrm{n}=102)$ \\
& & células $/ \mathrm{mL}$ & $(\mathrm{n}=7)$ & \\
\hline Citocentrifugação & $45,34 \pm 27,10^{\mathrm{b}^{* * *}}$ & $51,14 \pm 20,97^{\mathrm{b}^{*}}$ & $60,41 \pm 27,41^{\mathrm{b}^{* *}}$ & $50,32 \pm 27,47^{\mathrm{b}^{* * * *}}$ \\
Citometria de fluxo & $17,99 \pm 15,59^{\mathrm{a}^{* * *}}$ & $26,32 \pm 18,36^{\mathrm{a}^{* *}}$ & $41,53 \pm 22,08^{\mathrm{a}^{* * *}}$ & $25,71 \pm 21,24^{\mathrm{a}^{* * * *}}$ \\
Correlação & $0,481^{* * * *}$ & $0,293^{\mathrm{ns}}$ & $0,384^{*}$ & $0,496^{* * *}$ \\
\hline
\end{tabular}

${ }^{*} \mathrm{P}=0,03$.

${ }^{* *} \mathrm{P}=0,0007$.

**** $\mathrm{P}<0,0001$.

Letras diferentes indicam $\mathrm{P} \leq 0,05$.

ns: não significativo.

\section{DISCUSSÃO}

Os principais métodos aceitos e usualmente utilizados na detecção da mastite são a CCS e o exame bacteriológico (Della Libera et al., 2011). A CCS diferencial permite a diferenciação das populações celulares presentes no leite e, desta forma, possibilita a detecção da mastite logo no início do processo infeccioso, quando a CCS ainda é baixa (Rivas et al., 2001; Dosogne et al., 2003; Koess e Hamann, 2008). Entre os métodos aplicados para a contagem diferencial de leucócitos, podem-se citar a contagem microscópica direta por esfregaços, a técnica de citocentrifugação e a citometria de fluxo. A técnica de citocentrifugação apresenta as vantagens da rapidez de sua execução e da menor variabilidade em relação à contagem direta em esfregaços (Dulin et al., 1982). Do mesmo modo, a contagem diferencial pela citometria de fluxo tem sido associada à maior repetibilidade devido ao expressivo número de células avaliadas (Rivas et al., 2001; Dosogne et al., 2003; Koess e Hamann, 2008).
No presente estudo, o aumento da CCS automática apresentou correlação mais forte com a porcentagem de neutrófilos pela citometria de fluxo do que com a citocentrifugação. Provavelmente, isto se deve à quantificação das células epiteliais pela CCS automática pelo método Fossomatic (Koess e Hamann, 2008) e à presença dessas células dentro da população padrão estabelecida na citometria de fluxo, sendo que essas células não foram consideradas na contagem diferencial de leucócitos pela técnica de citocentrifugação.

Lee et al. (1980) relataram que a porcentagem de células epiteliais é praticamente nula nas secreções lácteas de bovinos nos distintos estágios da lactação. No entanto, Leitner et al. (2000), ao utilizarem anticorpos monoclonais para diferenciar as células epiteliais dos leucócitos (CD11a/CD18), indicaram que as células epiteliais são a população celular predominante em amostras de leite com baixa celularidade e que sua proporção é bem menor nas amostras de leite proveniente de mamas infectadas, embora, durante a fase aguda da 
mastite por coliformes, um grande número de células epiteliais seja eliminado no leite (Wagner et al., 2009).

Dosogne et al. (2003) encontraram correlação positiva e forte entre a porcentagem de neutrófilos pela citometria de fluxo e a contagem microscópica direta $(\mathrm{r}=0,90)$ em amostras com baixa CCS, embora não tenham utilizado anticorpo monoclonal específico para a identificação da população de neutrófilos. Do mesmo modo, Pillai et al. (2001), ao não utilizarem anticorpos monoclonais específicos para neutrófilos, encontraram correlação positiva e forte entre a porcentagem de PMNL e a CCS automática $(\mathrm{r}=0,89)$. A porcentagem de PMNL das amostras consideradas sadias e infectadas foi de 17 a $25 \%$ e de 33 a $49 \%$, respectivamente, semelhante ao observado no presente estudo, que utilizou anticorpo monoclonal específico para neutrófilos (Piepers et al., 2009; Pessoa et al., 2012), e ao considerar o limiar de 200.000 células $/ \mathrm{mL}$ para diferenciação entre mamas sadias e infectadas (Schepers et al., 1997; Pyörälä, 2003; Schukken et al., 2003; Della Libera et al., 2011).

Schwarz et al. (2011) consideraram que, em amostras de leite com $\mathrm{CCS} \leq 25.000$ células $/ \mathrm{mL}$, a população de linfócitos é a população leucocitária preponderante, sendo os neutrófilos a população predominante em amostras com maior celularidade, e os macrófagos a segunda população celular predominante em quase todas as amostras. O presente estudo corrobora esses dados, em que os neutrófilos foram a população celular predominante apenas nas amostras com alta celularidade $(<200.000$ células/mL).

Rivas et al. (2001) também relataram correlação positiva entre a porcentagem de leucócitos polimorfonucleares (PMNL) $\left(\mathrm{CD} 11 \mathrm{~b}^{+}\right)$pela citometria de fluxo e a porcentagem de PMNL pela citocentrifugação $(\mathrm{r}=0,82)$. No entanto, o CD11b é uma das cadeias $\alpha$ da $\beta_{2}$-integrina, que está envolvida no processo de migração celular (Paape et al., 2003), e pode ser expressa também por outras populações celulares, como exemplo a de linfócitos (Della Libera et al., 2012).

Corroborando ainda o presente estudo, Hoess e Hamann (2008) encontraram correlação positiva entre a porcentagem de leucócitos polimorfonucleares viáveis $(r=0,54)$ e de não viáveis $(r=0,389)$ pela citometria de fluxo e a SCC, sendo também encontrada correlação positiva entre a porcentagem de PMNL $\left(\mathrm{CD} 11 \mathrm{~b}^{+}\right)$pela citometria de fluxo e microscopia direta $(r=0,72)$, apesar de eles não utilizarem anticorpo monoclonal específico para identificação de neutrófilos.

Os resultados mostram que a citometria de fluxo pode ser uma ferramenta útil no diagnóstico da mastite bovina. Ainda, o presente trabalho é pioneiro na avaliação da correlação da SCC automática e da porcentagem de neutrófilos pela CCS diferencial pela técnica de citocentrifugação com a porcentagem de neutrófilos pela citometria de fluxo utilizando anticorpo monoclonal específico (CH138A) para esta população celular.

\section{CONCLUSÃO}

Os resultados deste estudo demonstraram que a correlação da CCS automática com a percentagem de neutrófilos por citometria de fluxo $(r=0,60)$ foi maior do que com a percentagem de neutrófilos pela técnica de citocentrifugação $(r=0,31)$. Conclui-se que a citometria pode ser uma ferramenta útil no diagnóstico e controle da mastite.

\section{AGRADECIMENTOS}

À Fundação de Amparo à Pesquisa do Estado de São Paulo (Fapesp), pelo apoio financeiro (Processo Fapesp 2009/50672).

\section{REFERÊNCIAS}

BRASIL. Ministério da Agricultura, Pecuária e Abastecimento. Instrução Normativa $\mathrm{N}^{\circ} 51$ de 18 de setembro de 2002. Regulamento Técnico de Produção, Identidade e Qualidade do Leite tipo A, do leite tipo B, do leite tipo $C$, do leite pasteurizado e do leite cru refrigerado e o Regulamento Técnico da coleta de leite cru refrigerado e seu transporte a granel. Diário Oficial da União, Brasília, 18 de setembro de 2002. Anexo II.

CUNHA, R.P.L.; MOLINA, L.R.; CARVALHO, A.U. et al. Mastite subclínica e relação da contagem de células somáticas com número de lactações, produção e composição química do leite em vacas da raça holandesa. Arq. Bras. Med. Vet. Zoot., v.60, p.19-24, 2008. 
DELLA LIBERA, A.M.M.P.; SOUZA, F.N.; BLAGITZ, M.G.; BATISTA, C.F. Avaliação de indicadores inflamatórios no diagnóstico da mastite bovina. Arq. Inst. Biol., v.78, p.297-300, 2011.

DELLA LIBERA, A.M.M.P.; BLAGITZ, M.G.; BATISTA, C.F. et al. Quantification of B and T lymphocytes subsets in bovine leukemia virus infected dairy cows. Sem. Ciênc. Agrár., v.33, p.1487-1494, 2012.

DOSOGNE, H.; VANGROENWEGHE, F.; MEHRZAD, J. et al. Differential leukocyte count method for bovine low somatic cell count milk. $J$. Dairy Sci, v.86, p.828-834, 2003

DULIN, A.M.; PAAPE, M.J.; WEILAND, B.T. Cytospin centrifuge in differential counts of milk somatic cells. J. Dairy Sci., v.65, p.1247-1251, 1982.

KOESS, C.; HAMANN, J. Detection of mastitis in the bovine mammary gland by flow cytometry at early stages. J. Dairy Res., v.75, p.225-232, 2008.

LEE, C.S.; WOODING, F.B.P.; KEMP, P. Identification, properties, and differential counts of cell populations using electron microscopy of dry cow secretions, colostrums and milk from normal cows. $J$. Dairy Res., v.47, p.39-50, 1980.

LEITNER, G.; SHOSHANI, E.; KRIFUCKS, O. et al. Milk leucocyte population patterns in bovine udder infection of different aetiology. J. Vet. Med. B., v.47, p.581-589, 2000 .

PAAPE, M.J.; BANNERMAN, D.D.; ZHAO, X.; LEE, J.L. The bovine neutrophil: structure and function in blood and milk. Vet. Res., v.34, p.597-627, 2003.

PESSOA, R.B.; BLAGITZ, M.G.; BATISTA, C.F. et al. Avaliação da apoptose de leucócitos polimorfonucleares $\mathrm{CH} 138^{+}$em leite bovino de alta e baixa contagem de células somáticas - dados preliminares. Arq. Bras. Med. Vet. Zoot., v.64, p.533539, 2012.

PILLAI, S.R.; KUNZE, E.; SORDILLO, L.M.; JAYARAO, B.M. Application of differential inflammatory cell count as a toll to monitor udder health. J. Dairy Sci., v.84, p.1413-1420, 2001.
PIEPERS, S.; DE VLIEGHER, S.; DEMEYERE, K. et al. Technical note: Flow cytometric identification of bovine milk neutrophils and simultaneous quantification of their viability. J. Dairy Sci., v.92, p.626-631, 2009.

PYÖRALÄ, S. Indicators of inflammation in the diagnosis of mastitis. Vet. Res., v.34, p.565-578, 2003.

REDELMAN, D.; BUTLER, S.; ROBINSON, J.; GARNER, D. Identification of inflammatory cells in bovine milk by flow cytometry. Cytometry, v.9, p.463468,1988

RIVAS, A.L.; QUIMBY, F.W.; BLUE, J.; COKSAYGAN, O. Longitudinal evaluation of bovine mammary gland health status by somatic cell counting, flow cytometry, and cytology. J. Vet. Diag. Invest., v.13, p.399-407, 2001

SAMPAIO, I.B.M. Estatística aplicada à experimentação animal. Belo Horizonte: Fundação de Ensino e Pesquisa em Medicina Veterinária e Zootecnia, 2010. 264p.

SCHEPERS, A.J.; LAM, T.J.; SCHUKKEN, Y.H. et al. Estimation of variance components for somatic cell counts to determine thresholds for uninfected quarters. J. Dairy Sci., v.80, p.1833-1840, 1997.

SCHUKKEN, Y.H.; WILSON, D.J.; WELCOME, F. et al. Monitoring udder health and milk quality using somatic cell counts. Vet. Res., v.34, p.579-596, 2003.

SCHWARZ, D.; DIESTERBECK, S.; KÖNI, S. et al. Flow cytometric differential cell counts in milk for the evaluation of inflammatory reactions in clinically healthy and subclinically infected bovine mammary glands. J. Dairy Sci., v.94, p.5033-5044, 2011.

WAGNER, S.; JONES, D.E.; APLEY, M.D. Effect of endotoxic mastitis on epithelial cell numbers in the milk of dairy cows. Am. J. Vet. Res., v.70, p.796-799, 2009. 